\title{
Study on the internal flow law of cross wedge rolling of aluminum alloy based on finite element analysis
}

\author{
Wen-shengYUAN ${ }^{1, \mathrm{a}}$, liTao ${ }^{1, \mathrm{~b}}$, Zhong-leiWANG ${ }^{11, \mathrm{c}}$, Zhao-dongLI $\mathrm{LI}^{1, \mathrm{~d}}$ \\ 1.School of Mechanical and Electronic Engineering, Shandong Jianzhu University, \\ Jinan, Shandong, 250101 \\ ajnrapid@163.com b15662404420@163.com Wade_Thunder@163.com \\ dLi.zhaodong@163.com
}

Key words: cross wedge rolling, aluminum alloy, metal flow, rolling force

Abstract: the cross wedge rolling technology, as an effective method of shaft forming, has been paid more and more attention. With the development of the car's lightweight, aluminum alloy with its high quality performance, as a substitute for the best choice of structural steel. Steel of shaft parts by cross wedge rolling technology by both foreign and domestic experts and scholars research and practical production experience accumulation, has perfected a process, but because of the aluminum alloy metal microstructure and properties, structure and deformation characteristics are iron and steel has a big difference, and cross wedge rolling in the rolling process, the deformation of workpiece complex, the materials of different makes the selection of process parameters is not the same, so in this paper, the research on aluminum alloy wedge cross rolling process and organizational performance, forming of aluminum alloy workpiece and deformation of understanding have important significance.

\section{Introduction}

Aluminum and its alloys are widely used in nonferrous metals, which is widely used in nature. With its light weight, high strength, good plasticity, good thermal conductivity and so on, in the application of the metal products only after steel. Along with the rapid development of aviation, spaceflight, automobile industry, petroleum chemical industry, machinery and electrical appliances, electronic communication, medical equipment and other new industries the rapid rise, the application of aluminum alloy materials increased dramatically, is becoming more and more important in the national economy. With the development of social economy, the problems such as the shortage of the environmental pollution, energy and resources becomes more and more serious, how to in metal processing, improve product material use rate, save energy and resources has become a new research direction. With the traditional method of shaft parts production, cross wedge rolling process in the use of materials and production efficiency has a significant increase. As a kind of near net forming process, the technology of cross wedge rolling has been paid more and more attention.

Steel of shaft parts by cross wedge rolling technology by both foreign and domestic experts and scholars of many years of research, technology has become increasingly mature, whether in the mold design, processing and equipment operation have formed a relatively perfect system. But because of the aluminum alloy metal microstructure and properties, structure and deformation characteristics are steel and has a larger difference, and cross wedge rolling in the rolling process, the deformation of workpiece complex, the materials of different makes the selection of process 
parameters is not the same, so in the research of steel cross wedge rolling process based on to the metal properties of aluminum alloy material carries on the analysis, the research, in order to select the optimal technological parameters for rolling aluminum alloy billets.

\section{Characteristics of aluminum alloy deformed material}

Industry in general according to the number of elements, the aluminum and aluminum alloy deformation aluminum alloy and cast aluminum alloy, deformation of aluminum alloy can be classified as industrial pure aluminum, heat treatment can not be strengthened aluminum alloy and heat treatment can enhance the aluminum alloy.

Which is used in the forging of aluminum alloy Al-Si-Cu system, such as 6A02, 2A70, 6063 and other alloys, with good plasticity, good forging performance. Generally used in aviation, marine, construction and other aspects of the requirements of the medium strength of the forgings or die forgings. Its deformation characteristics are: (1). The deformation temperature range is narrow. The deformation temperature of the majority of aluminum alloy at 450 350 is 470 , and the deformation temperature range is about 100 . The thermal conductivity of aluminum alloy is more than twice the iron, in the rolling process, mold temperature drops quickly, led to a rapid decline in aluminum alloy rolling temperature, the rolled pieces of plastic reduce, deformation resistance increases, therefore, in the rolling process ensure the mold temperature is the key to improve the quality of rolled products. (2). The flow stress of aluminum alloy increases with the increase of strain rate. Strain rate increase is that the dislocation to reply, the process of hardening significantly, plastic performance is significantly lower. (3). The cross wedge rolling process is a continuous large plastic deformation process, due to the activity of aluminum alloy, in the rolling process workpiece will adhesion in the mold and greatly reduce the service life of the die, and even the dies and the workpiece to be scrapped.

Cross wedge rolling process is a complex and continuous plastic deformation, according to the deformation is divided into four parts, wedge, wedge formation, stretching segment and fine the whole paragraph. Wedging zone is mold in the rotation process, the mould wedge initial part on the workpiece forming $\mathrm{V}$-shaped groove, and drives the rolling start rolling, V-shaped groove from shallow to deep; wedge formation is under the effect of the mold and the V-shaped groove gradually widened, and gradually deepened; stretching segment is V-shaped groove depth did not change, only the width of the $\mathrm{V}$-shaped groove gradually along the radial direction becomes larger, the finishing section is on the workpiece size and surface shaping, in order to improve the quality and accuracy of parts.

\section{Finite element theory in the process of cross wedge rolling}

Basic hypotheses. In cross wedge rolling, rolling in the plastic deformation occurred at the same time, also has elastic deformation. If on the analysis of the two kinds of deformation are taken into account, will make the calculation becomes very complex, but due to the elastic deformation of the row variables and plastic deformation is very small compared, so elastic deformation of row variables to calculate the influence is very small and can be ignored. So when the rolling simulation experiment, the workpiece as a rigid plastic material to calculate.

\section{Establishment of rolling model of cross wedge rolling}

Establishment of geometric model. In rolling process, rolling occurs deformation of the radial, axial and transverse three direction, deformation is a complex process, the establishment of 
three-dimensional model of the workpiece and die, and is similar to the actual production of cross wedge rolling model is established, reduce rolling simulation in distortion, can be a good reflection of cross wedge rolling rolling process, simulation results closer to the actual. First is to design the shape of the rolling parts out of cross wedge rolling die cavity, the geometry model of the rolling, roll and a baffle plate is established by UG, to establish the geometric model of cross wedge rolling, as shown in Figure 2.1, and to *.stl file format saved.

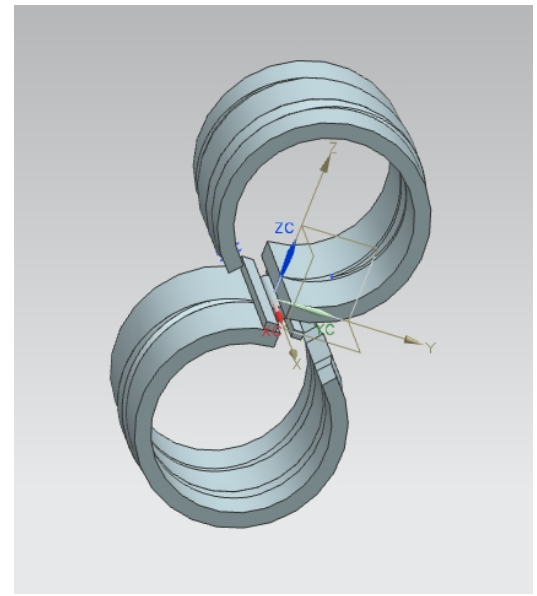

Fig.1 Geometric model of cross wedge rolling

The establishment of physical model A good geometry model is introduced into DEFORM-3D to establish its physical model. The establishment of the physical model is the key link in the simulation, the physical model is reasonable not only affect the speed of the simulation, but also affect the accuracy of the simulation. In the establishment of physical simulation model of cross wedge rolling, with the principle of the finite element analysis as the basis, comprehensive consider various influencing factors of cross wedge rolling process, in the repeated test simulation and Optimization Based on established a closer to actual rolling simulation model and improve the solving efficiency and precision of the simulation.

The establishment of the main steps of the physical model of cross wedge rolling is: choose reasonable finite element unit; setting material model; carries on the grid division of the workpiece; definition of workpiece and die contact conditions and initial conditions; on the workpiece and die for imposing constraints and load.

\section{Analysis of aluminum alloy rolling within the metal flow law}

With the method of net rolling deformation observation. Through the finite element mesh on the strip, you can see the visual changes in the metal workpiece and characteristics before and after rolling. Rolled strip in axial incision, and the axial area is divided into a plurality of square composition, Fi.2 for the workpiece in rolling process, axial section on the grid change

char
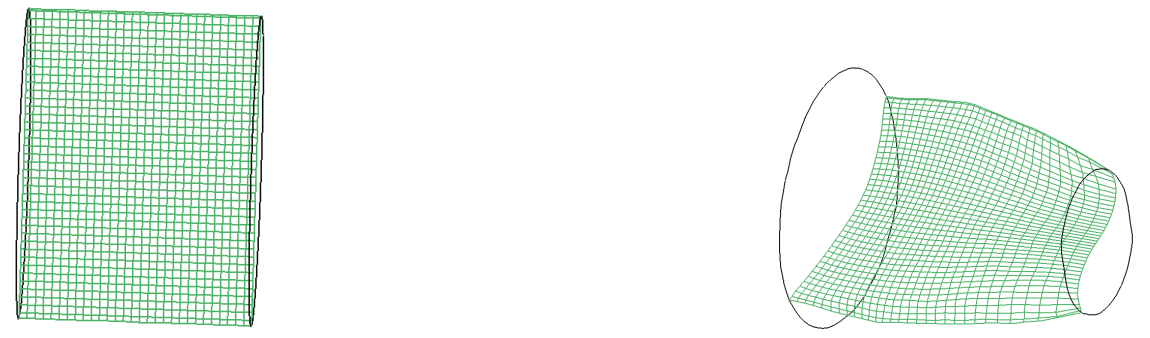


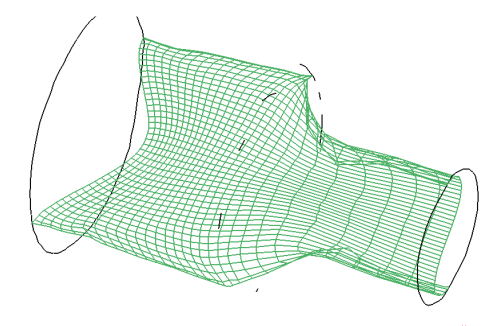

(a)Before rolling stock (b) Finish rolling wedge section(c) After the completion of rolling workpiece

Fig.2 The mesh deformation map

From Figure 3.1 can be seen in rolling zone, severe deformation of the grid, in front of the rolling, grid is a square, but after rolling, the mesh in the radial direction of the length of the shorter, that is, radial compression, grid on the axial length of variable length, that is, extending in the axial direction, at the same time near the workpiece surface, the grid is distorted, workpiece did not enter the rolling process of the part is basically a square, in the end surface of the workpiece appear sunken heart.

In rolling deformation zone, workpiece surface grid along the axis occurred in reverse, the rotation direction and workpiece rotating in the same direction, as shown in figure 3.1(c)for rolling grid changes. The reason for this is that due to the mold rotation is driven by the friction force between mold and slab, mold in the rotation process, in the mold on the workpiece applied is pressure at the same time, on the workpiece applied friction and as shown in the figure 3.1(c), mold surface by friction torque makes the workpiece torsion deformation and rotation.

Analysis of axial flow rolling by displacement method. In order to can visually observe rolling inside the metal flow using DEFORM-3D finite element software tracking point displacement method to achieve. The selection of a uniform point on the rolled pieces as tracking, which can better reflect the rolling deformation zone of the metal flow, first along the axial direction of the workpiece selected six cross-sectional, namely a, B, C, D, e, F, as shown in the figure. According to the principle of constant volume before and after rolling, to calculate the rolling coins all cross sections of location on the workpiece, as shown in figure 3.2-A, B shows, and in each section from the center to the workpiece surface equidistant selected 11 points, as shown in figure 3.2-c. Figure 3.3 variation of relative displacement for the workpiece in rolling process at different stages of the 11 point tracking axis.

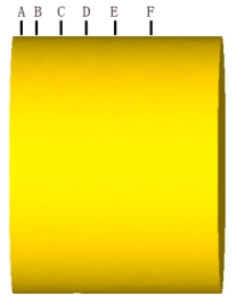

(a) After rolling section (b) Cross section

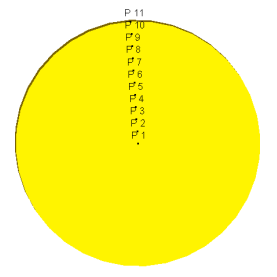

(c) Location of cross section tracking point

Fig.3 The tracking point position map 


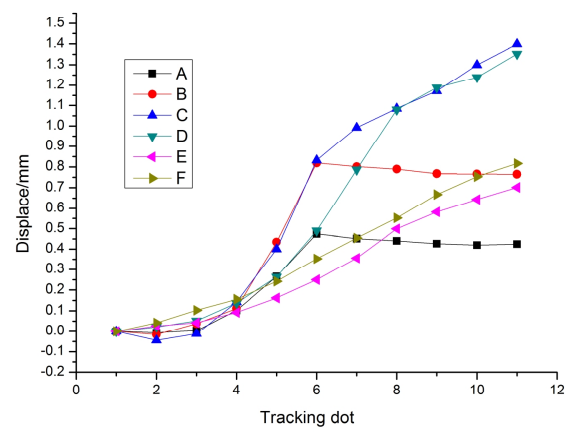

(a) At the end of the wedge

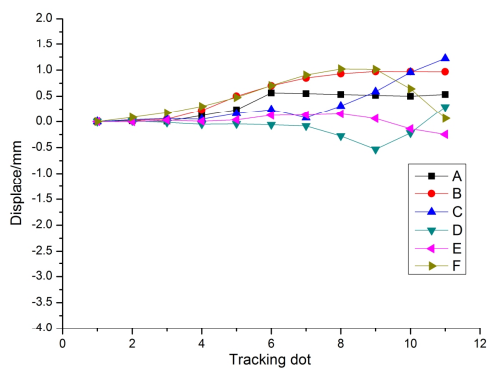

(c) At the end of the stretching section

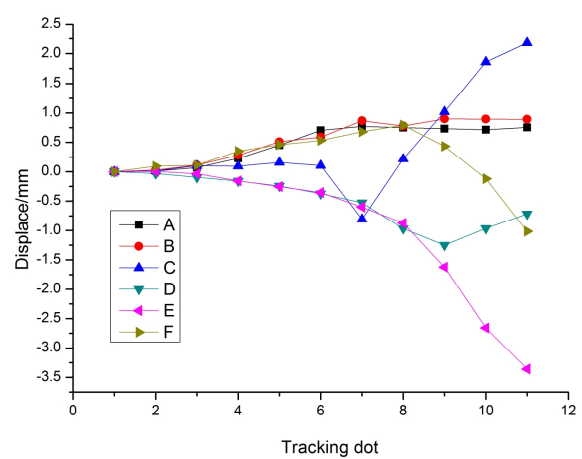

(b) Stretching section

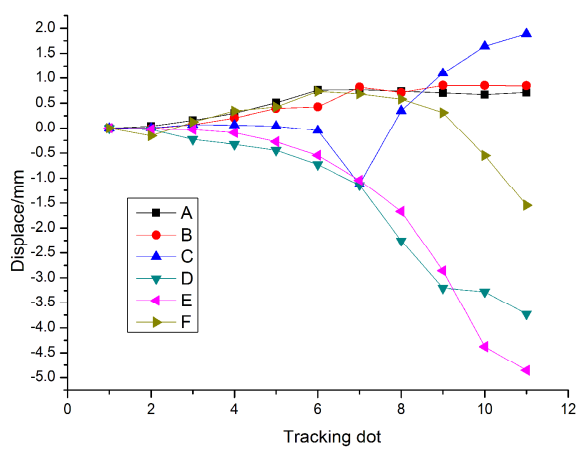

(d) Rolling finish

Fig.4 The relative displacement of the tracking points in different stages

From the Fig.4(a) seen, all sections of tracking point from the point of 4 axial displacement increased rapidly, sections a and B from tracking point 6 start point on the surface of a metal began to lag behind the internal, Section $\mathrm{c}, \mathrm{d}$, e and $\mathrm{f}$ axial displacement relatively before increase, which section $\mathrm{c}$ and $\mathrm{d}$ on the axial moving a large. Fig.4(b) rolling in broadening stage of each section the axial displacement diagram, sections a and b on the axial relative movement is relatively small, Section $\mathrm{c}$ and $\mathrm{d}$ on the axial relative displacement changes violently, sections e and $\mathrm{f}$ of workpiece surface point 1 lag at a point on the rolling within the. Fig.4(c). Each section of the axial relative displacement changes little, but the workpiece from the Fig.4(b) to, sections Fig.4(c) a and b have been over rolling process, which the axial relative displacement is constant, but in Section d rolling within the axial relative displacement than outside the mobile from from the small, section e and $\mathrm{f}$ section internal point of workpiece than outside the relative displacement. Finish rolling cross section of the axial movement of the displacement change chart, sections a, b and c, and the Fig.4(c) cross-section changes similar to Fig.4(d). Section d, e and f of workpiece surface lag points and the Fig.4(c) compared, increased.

Due to the activity of aluminum alloy, in the process of rolling aluminum alloy strip, from the blank internal exposed fresh metal surface often die on the viscous large, leading to the workpiece in rolling contact zone on the deformation resistance becomes large, the rolling surface of the metal layer of the degree of the metal flow becomes smaller, and rolling within the metal by mold, forcing along the axial larger flow of metal, metal on the surface of the workpiece due to the deformation resistance increases, the metal flow resistance large, so the lag on the internal, and the region with the change of rolling area and change. Away from the rolling zone after deformation, the surface of the metal workpiece in the axial rolling zone under the action of the advance and the points inside 
the workpiece

The internal strain of workpiece. The strain is rolling in the rolling process of the plate to measure physical quantities of plastic deformation. Here on the strip are discussed in the strain parameter of each point.

Fig. 5 The distribution curves of the P1, P2, P3, P4 and P5 in the radial direction of the variable with the rolling time. From the figure can be seen in rolling process and the change trend of the strain is basically the same, from the beginning of the wedging zone, increase gradually from zero, when into stretching stage to increase the speed to slow down, rolling into fine adjustment period, the size of strain remained invariant. The strain is always negative, namely in the rolling process, the workpiece is always along the radial compression deformation. Rolling into stretching stage, P3, P4, P5 strain in the radial fluctuations, P1, P2 radial strain fluctuations in the smaller, the state and remained there until finishing section.

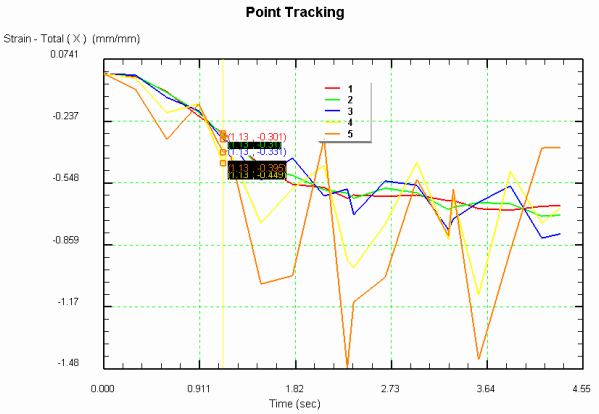

Fig.5 The radial strain changes with time

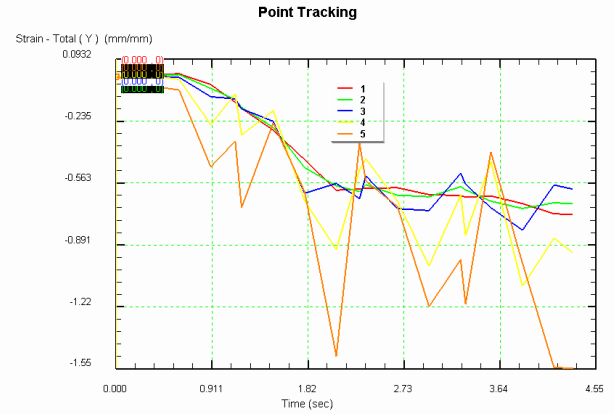

Fig.6 Cut the workpiece changes to the strain with time

Fig. 5 the distribution curves of strain versus rolling time in tangential direction. From Fig.6, we can see that the tangential strain variation trend is consistent, rolling into the wedging zone, the points are in a period of time occurred cut to the normal strain, that is, cut to extend, along with the rolling, rolling the strain variable compression strain, and gradually increased, when into stretching stage, compressive strain increased speed slow and stable in certain numerical. From Fig.6 the strain values and fluctuations in the size of the point of view, from the core track points P1 to workpiece surface P5 point, the strain value and the fluctuation amplitude is increased gradually, namely core of rolled piece cut to strain than cut of the workpiece surface to strain, such as in Figure 3.1 rolling occurred along the axis of the torsion.

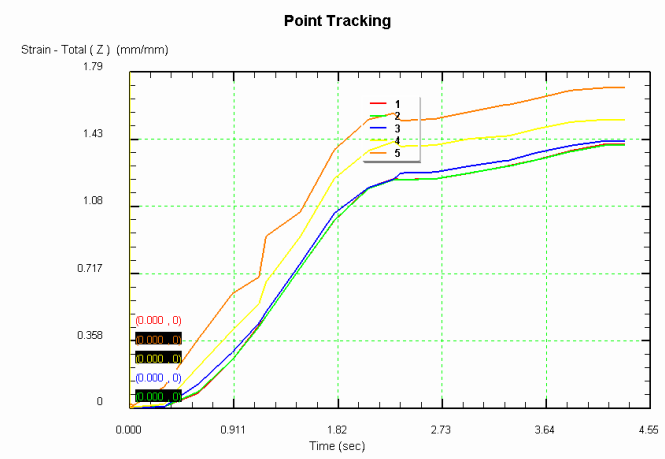

Fig.7 The axial strain changes with time

Fig.7 The distribution of the strain along the axial strain of the various points along with the 
time variation of the rolling. It can be seen from the figure from the strain on the rolling track point by strain is always positive, namely axial extension. The strain values from the workpiece into wedging zone increased gradually with the increase of axial deformation, until the workpiece into stretching stage, axial strain growth trend remains unchanged, when the rolling into the finishing section, owing to the decrease of the axial deformation of rolled piece of growth, the axial strain of rolling increasing trend slowing. Rolling heart of tracking points P1, P2 axial strain curves coincide, tracking point P3 axial strain curve and P1, P2 is basically similar to the, but the strain value is slightly larger than that of P1 and P2 strain value. Strain values of P5 and P4 gradually increased. From the point of view of the overall trend, rolling within the axial strain value less than the value of the strain of the surface and workpiece has been the tensile strain.

\section{Conclusions}

By grid method and displacement method are used to observe in the rolling process, rolling inside the metal flow rule, the rolling of metal along the axis of torsion, radial compression and axial extension. With the rolling, because of aluminum alloy workpiece surface metal of mold has certain adhesion force, hindering axial flow of metal, the rolling within the gradually advance on the surface of the workpiece.

The workpiece by radial and tangential strain is mainly compressive strain, axial strain and tensile strain is mainly. From each point by strain with time variation diagrams can be seen in the radial and cut to strain is mainly compressive strain variation trend is largely the same, stretching segment at the end, the strain values reached maximum, the heart of the maximum radial and tangent to the strain respectively -0.686 and -0.732 , the maximum axial strain for 140.5 . From the heart to the external strip rolling, the strain value increases gradually, which is one of the important characteristics of cross wedge rolling technology.

.Workpiece in rolling process, has always been "two tension compression" positive stress, axial and cut to tensile stress, the radial compressive stress. The strain by "two pressure pull", namely, radial and tangential compressive strain, axial tensile strain

\section{Reference}

[1] Tian Rongzhang, Wang Zhutang. Handbook of aluminum alloy and machining[J] Machinery Industry Press 2000

[2] Handbook of nonferrous metals materials [M]. Chemical Industry Press, 2005

[3] special alloy and its forging [M]. National Defence Industry Press, 2009

[4] Yuan Wen Sheng, Wang.Zhong Lei Based on Delphi cross wedge rolling die CAD system. [J].Forging equipment and manufacturing technology, 2005 (6): 93 to 95.

[5] Wang Lei, Huang Rugang, Yuan Wensheng. Study on the rolling forming of aluminum alloy and the status [J]. Forging equipment and manufacturing technology, 2012,05:17-20.

[6] Li Wenchao. Study on the surface defects of the shaft parts wedge cross rolling [D]. Jilin University, 2010

[7] Gong Guichun. Based on the research of the DEFORM--3D research on the forming rule of the aluminum alloy hollow shaft parts [D]. Jiangsu: Jiangsu University, 2010

[8]Chen Jun, Wang Yu Guo, Wang Yue Xian, Metal plastic forming finite element simulation of hexahedral element division technology research progress [J ]. plastic engineering journal, 9, 2002 (3)

[9] Li Yao, metal plastic forming principle [M]. Machinery Industry Press, 2004.7 
[10], Wang Zhonglei, Yuan Wensheng. The cross wedge rolling forming process demonstration system research and development of [J]. Forging equipment and manufacturing technology, 2006 (4): $73-75$

[11] Li Zongyao. The present situation and development trend of aluminum processing industry in our country and Its Countermeasures [J]. aluminum alloy processing technology, 1995, 1-8. 